\title{
Nuclear power, public interest and the professional
}

In the case of major and complex technological decisions in our time, such as that on nuclear power, it is sometimes said that the public is unable to make a full evaluation on its own and needs to trust some established professional and political mechanism instead. Jan M. Döderlein of the Institutt for Atomenergi, Norway, comments on the roles of the professionals and the nuclear critics.

NUCLEAR technology came to maturity at a time when attention was rightly focused more than before on the environmental aspects of industrial and energy production. As a result, in many countries nuclear stations are the only type of electric power plant for which detailed safety and environmental evaluations by government agencies are required, and where these evaluations are open to direct public participation. This has helped to create a public controversy over nuclear power, a controversy which appears in large measure to have spread from the United States. It presently focuses on three main topics: nuclear reactor accidents, the handling of radioactive waste, and the increased risks of proliferation of nuclear weapons (and therefore presumably of nuclear wars) from an expanding peaceful use of nuclear power.

Probably no technological decision in the history of mankind has been the subject of so many detailed studies, so much open discussion and such broad public participation. Amongst it all, some nuclear critics have given prominence to ethical aspects of the nuclear decision. This is justifiable to a certain extent since the application of nuclear power-indeed of any power-raises ethical questions. To carry this view to extremes in the way it is sometimes done, however, represents a vain attempt to set aside fundamental laws of nature and society.

One aspect of such ethical considerations is seldom if ever mentioned. The number of publications on astrology, on transcendental meditation, on nirvana and similar subjects is increasing sharply. Among the younger generations, and in some leading cultural and political groups, increasing numbers of people are seeking mystical or irrational escapes from many realities of modern society. There are thus clear indications that superstition, mysticism and emotionalism are on the upsurge.

Another symptom of this surge of emotionalism is the apparent tendency among sensitive and highly responsible citizens to shoulder the burden of guilt associated with the expansion of modern society. With some leading personalities in politics, industry and science, this burden is transformed into a desire to steer the development of society away from perceived future cataclysms. Sometimes the bases for assuming such cataclysms are world models created by scientists. These provide some predictions of a near disastrous future for our society with the combined authority of science and leading personalities in society. Such an authority is merited neither by the quality of the world models nor by their basic assumptions.

One of the consequences of irrationalism and emotionalism is a desire for simplification of life and for a low energy society, a desire which is reinforced by "scientific" doomsday prophecies. Another is a strong sentiment against the people who are working for the application of technology within society, which erodes confidence in expertise. Nuclear power is not a simple technology; it can produce prodigious amounts of energy; emotionally it can be construed as having a certain "doomsday character"; and it requires qualified expertise. Nuclear power can therefore be seen as the antithesis of irrationalism, a view which easily creates a strong, emotionally based anti-nuclear attitude.

\section{A natural outlet}

The nuclear controversy is therefore a natural outlet for many irrational needs in our society, not least important of which are the irrational needs of many scientists, technologists and experts. These views are supported and broadened by fundamental observations made in another context by the epistemologist Karl Popper. He stated that, when threatened,

"the rationalist attitude to social and economic questions could hardly resist when historicist prophecy and oracular irrationalism made a frontal attack on it. This is why the conflict between rationalism and irrationalism has become the most important intellectual and perhaps even moral issue of our time".

One perspective on the nuclear debate, then, is that our dominant problem may be that of fighting emotionalism and irrationalism. This is not to use the words "irrational" and "emotional" not against emotions or the irrational. The issue is the application of irrationalism and emotionalism in attacking major problems of our real, physical world. in any derogatory sense. The fight is
The emotional and ethical aspects of nuclear power are trumpeted particularly by two groups of critics having the common denominator of emotionalism. One group consists of people for whom nuclear power is a vehicle of self-realisation. They play out some of their inner and emotional needs by taking an active part in the nuclear controversy, and the factual nuclear issues seem to play a secondary role. The other emotional group of nuclear critics is composed of professional and amateur politicians, notably leftist groups, anarchists, some populists and some environmentalists. Nuclear questions, real or imagined, are a means by which they further their own political goals, sometimes clandestinely, sometimes openly. A very different group of critics, the opportunists and malcontents, is cynically achieving fame and prominence by going into the nuclear debate, writing in the newspapers, giving lectures, going on television and so on. Needless to say, similar people are also found in the so-called nuclear community.

\section{Characteristic shared}

All three groups of nuclear critics share one characteristic: they seem to accept authoritarianism as a road to knowledge, often to the exclusion of other sources of knowledge. They rarely support their assertions with reasoned arguments or with facts, and they consistently invoke the opinions of some distinguished scientists, some Nobel-prize winners or some professional societies, ignoring others who disagree with their views. By confusing technical facts which can never be argued qualitatively, with value-judgments which can always be argued, the critics have in some countries succeeded in misleading sections of the public, causing them to believe that everything is open to argument and that the experts are confused. The truth is that the experts are not confused in their own field of expertise. Outside their own field they are not experts.

In the past two years we have seen a plethora of manifestos and statements for or against nuclear power by Nobel prize winners, by groups of scientists and by various professional societies. In connection with the statements, the eminent or special qualifications of the participants are always emphasised. While possibly not without merit, such statements should be viewed very critically. Practically without exception the participants in the anti-nuclear manifestos have no technical background in fields relevant to nuclear technology. Against the participants in pro-nuclear 
manifestos, this criticism is less relevant.

One criticism is valid against all manifestos on nuclear power. The scale and timing of the introduction of nuclear power is a major and complex decision, resting on technical, economical, political and other social considerations. In a democratic society such decisions are not left to technological experts but to elected political officials. A professional using his specialist background in support of personal views on social questions tries to carry his professional authority over into fields where he should no longer have such authority, into fields where his opinions should be weighted on the "one man, one vote" principle.

Members of some professions believe they have more specialised knowledge, and that their political conclusions are based on sounder analysis of the evidence than the public. If one expects the public to have confidence in the role of professionals in decisions, the opinions of highly regarded experts within their chosen profession must be accorded a certain authority. But it is equally important not to support a carry-over of professional authority to political and ethical questions, a carry-over which may indicate a certain intellectual arrogance.

\section{Assessing the 'facts'}

Many "facts" in the nuclear controversy are to all appearances hotly contested. Some of these "facts" are not really facts, and deserve to be independently and critically evaluated by professionals and non-professionals alike. Among such "facts" in the nuclear debate are some aspects concerning the long term effects of radioactive waste, and the possible connections between nuclear power and proliferation of nuclear weapons.

Among the often repeated and confusing statements on radioactive waste are the suggestions that in this waste man produces materials that (uniquely) remain toxic for times much longer than we have had experience with, and that in nuclear reactors we have created materials that have never existed before.

Certain elements created in substantial quantities by nuclear power, for example plutonium (but not waste proper), remain toxic for times longer than the period of human civilisation. No industrial scale method for disposing permanently of radioactive waste is in use today. Deciding on appropriate handling of this waste is an important and difficult question which many countries are addressing. At a pilot plant level, however, there are solutions to the technological problems. Moreover the long life of radioactive waste should not be judged in isolation; industry including power production from oil and coal gives uncontrolled releases to the environment of substances which remain toxic for infinite times; civilisation is accustomed to living with poisonous materials that remain toxic for times longer than the life of radioactive substances. For civilisation as we know it there is thus only a choice of which toxic materials we wish to handle.

With nuclear power man has not created any materials new to earth. Specifically, fission products and plutonium are naturally occurring elements, albeit in small concentrations. The ethical objection to nuclear power sometimes made on the basis of creation of "new" elements therefore has no foundation in fact.

The question of a possible connection between nuclear power and proliferation of nuclear weapons really has two separate aspects: one concerning subnational groups using atomic explosives for terrorist purposes, the other concerning a possible increase in the number of sovereign nations with access to nuclear weapons. The understandable but unfortunate preoccupation of the mass media and the public with the matter of nuclear terrorism is distracting our attention from the far more important question of possible proliferation of atomic weapons beyond the present weapons states.

It is misleading to ask whether the spread of nuclear power inevitably leads to the spread of nuclear weapons. The peaceful uses of nuclear technology are now widespread; there are substantial quantities of peaceful and military fissile materials. The relevant question is whether a halt to the expansion of nuclear power, or to all use of nuclear power, will substantially reduce the potential for wars and the risk to the public from wars. Clearly it would not be meaningful to curtail the use of nuclear power for this reason without at the same time dismantling the many smaller reactors used for medical purposes, isotope production and research in most countries of the world. This aspect takes on added importance when one considers the substantially more complex operations required for using a power station rather than a small reactor for plutonium production.

Technological developments are likely to complicate further our questions about weapons proliferation. Within a few years there will be available, worldwide, several new techniques for enriching uranium. All of those being researched today are potentially simpler technologically than the present diffusion technique, and all of them can more easily be applied on a small scale. Ensuring peaceful uses only of these techniques may be of more importance than the question of plutonium safeguards.

Unfortunately, nuclear proliferation is only part of a more fundamental and more serious contemporary question: can anything short of actual war stop a determined sovereign nation from getting primitive but usable versions of any kind of contemporary weapons technology-nuclear, bacterial, chemical or any other? Be that as it may, broad agreement could probably be obtained to curtail development of nuclear power if rational arguments could support an assertion that stopping peaceful uses of nuclear energy would reduce, if only marginally, the risk to the public from war and acts of terrorism. But reasonable, rational and valid arguments to this effect have not been put forward so far.

\section{Reducing the risks}

On this basis, expending efforts to stop the use of nuclear power does not seem to be a credible and useful way of reducing the risks of nuclear wars. Our most responsible and efficient attack on the nuclear proliferation problem would seem to be to channel our efforts into support for the UN and the nuclear supplier nations in their non-proliferation efforts; into the expansion of international safeguards inspection, including inspection of arrangements to protect physically all fissile material; into support for all practicable means of making the time span and the effort involved in converting in-reactor plutonium production to a workable nuclear weapon as large as possible; and last but not least into the problems created by the avajlability of new uranium enrichment techniques.

All human actions entail some unforeseeable consequences. Plans for action cannot be based solely on factual proofs and logical deductions; they must finally rest on political decisions made in the face of uncertainty, a point which gives a perspective on the place of technological facts in a world of values and emotions. Clearly, a number of irrational, emotional and ethical factors may be and should be of importance in a choice of power plants for the production of electricity. But an evaluation of rational and quantifiable factors tells us how many lives, which environmental improvements and what economic advantages we have to sacrifice in order to satisfy such emotional demands. In defining the role of the professional and in protecting the public interest, the importance of emotional factors in the nuclear controversy must be admitted; but as many problems as possible should be decided on a reasoned. factual and rational basis. 